\title{
Validity of Wait Time Complaints and Effect of Trainee Presence in an Ophthalmic Emergency Department
}

\author{
Annika J Patel, Zahra Markatia, Jayanth Sridhar, Kara M Cavuoto \\ Bascom Palmer Eye Institute, University of Miami Miller School of Medicine, Miami, FL, 33I36, USA \\ Correspondence: Kara M Cavuoto, Bascom Palmer Eye Institute, University of Miami Miller School of Medicine, 900 NW Ith Street, Miami, FL, \\ 33136, USA, Tel + I 305-326-6324, Fax + I 305-547-3675, Email kcavuoto@med.miami.edu
}

Purpose: Press Ganey (PG) surveys can provide a more comprehensive evaluation of specific patient complaints through input of comments. In this paper, we evaluate the validity of wait time complaints submitted via PG surveys in an ophthalmic emergency department (ED) and determine the effect of trainee presence on total time spent in the ED and negative PG comments.

Materials and Methods: This was a retrospective study evaluating PG reports for ED demographic, diagnostic, visit time and trainee involvement trends.

Results: Females made up 48.0\% (4465) of overall ED patients yet submitted 62.8\% (98) of the negative comments on PG surveys. More than a quarter $(27.7 \%)$ of the negative comments pertained to wait time. Patient-reported times spent in the ED were significantly longer than actual total ED times $(\mathrm{p}<0.001)$. Both reported and actual total ED times were significantly longer for patients who submitted wait time negative comments than those with other complaints $(p<0.001$ vs $p=0.039$, respectively). Patients seen by residents spent a significantly longer time in the ED than those seen by non-resident providers $(\mathrm{p}=0.015)$, although self-reported total ED times did not differ significantly in these patients $(p=0.467)$.

Conclusion: Patients submitting complaints about wait time and those seen by treatment teams including residents spent a significantly longer time in the ED. Although PG survey respondents are not representative of the overall ED patient population, this highlights the need for academic institutions to seek methods to maximize efficiency in patient care without compromising trainee education.

Keywords: workflow, patient satisfaction, resident, fellow

\section{Plain Language Summary}

The authors conducted this study to assess wait times and visit times at an ophthalmic ED. They found patients who complained about wait times ended up waiting significantly longer than those who had other complaints. Also, patients who were seen by a team that included a resident spent a longer time in the ED than those who were not. Overall, this demonstrates patient complaints about wait times are likely valid and trainees such as residents may play a role in slowing down clinic flow. While trainee education is vital in academic institutions, programs should seek ways to increase workflow efficiency to compensate for clinic flow slowdowns.

\section{Introduction}

Press Ganey (PG) surveys are used across the American healthcare system to provide feedback on patient experiences. ${ }^{1}$ Their use has been controversial due to selection bias, nonresponse bias, and effect of patient demographics on survey scores. $^{2-4}$ However, PG surveys include the option for input of comments that may allow for a more comprehensive evaluation of specific patient complaints. A prior study demonstrated that the most common complaints in the emergency department (ED) are related to long wait times. ${ }^{5}$ Long wait times have been associated with poorer health outcomes and thus merit analysis as an area of institutional and departmental improvement. ${ }^{6,7}$ However, they are difficult to eliminate at a teaching institution that gives residents the opportunity to evaluate patients and construct an initial impression and plan. 
The presence of residents is imperative for trainee education and building confidence through real-life experience. ${ }^{8,9}$ However, longer appointment times for patients in the presence of trainees have been demonstrated in ophthalmology clinics and pediatric EDs. ${ }^{10-12}$ This study utilizes PG survey reports at an urban academic ophthalmic ED to evaluate the degree of survey representation of the overall ED population, validity of wait time complaints, and effect of trainee presence on total time spent in the ED.

\section{Materials and Methods Study Design and Setting}

This cross-sectional study was approved by the Institutional Review Board at the University of Miami (\#20200719), complied with the Health Insurance Portability and Accountability Act, and adhered to the tenets of the Declaration of Helsinki. A retrospective study of demographics, negative complaints, and treatment teams of patients submitting PG surveys in an ophthalmic academic ED was conducted using PG summary reports and ED fiscal year reports.

\section{Selection of Participants}

All patients who submitted negative comments in PG surveys between 5/6/20 and 10/11/20 ( $n=92$ ) were included. This data was compared to demographic information of the entire patient population visiting the ED for the same time period $(\mathrm{n}=9304)$.

\section{Measurements}

PG reports and ED data were evaluated for diagnosis, gender, language, shift time, and negative comments. Negative comments were categorized into "Wait Time" or "Other" based on content by one of the authors (AP). Reported and actual total ED times, as well as composition of management teams were collected from PG reports with negative comments.

\section{Analysis}

Data was organized using Excel 2018 (Microsoft, Inc., Redmond, Washington), and statistical analysis, including independent sample $t$ test, paired sample $t$ test, Kruskal-Wallis test, and Chi square test, was completed using SPSS version 25.0 (IBM, Armonk, New York) with significance of $\mathrm{p} \leq 0.05$.

\section{Results}

\section{Patient Demographics}

There were 156 negative comments submitted by 92 different patients. Survey questions are shown in Table 1 . Breakdown of number of negative comments and number of comments per survey submitted by gender, language, and shift seen is displayed in Table 2. Although females made up 48.0\% (4465) of 9304 overall ED patients, they submitted $62.8 \%$ (98) of the negative comments. Additionally, females submitted more negative comments within one survey than males (female average 1.81 comments/survey vs males average 1.53 comments/survey); however, the difference was not statistically significant $(\mathrm{p}=0.234)$. There was no difference in the number of negative comments per survey by language $(\mathrm{p}=0.668)$. Patients seen in each shift submitted a proportionally equal number of negative comments per survey $(\mathrm{p}=0.390)$, and total time spent in the ED was not found to be significantly different across the various shift times $(\mathrm{p}=0.957)$.

\section{Validity of Wait Time Complaints}

Reported and actual total ED times were significantly different for all patients that submitted negative comments (reported: mean 213, SD 100 minutes, actual: mean 154, SD 98 minutes, $\mathrm{p}<0.001$ ). Patients who submitted negative comments pertaining to wait time had significantly longer reported (wait time comments: mean 269, SD 109 minutes vs other comments: mean 192, SD 88 minutes, $\mathrm{p}<0.001$ ) and actual (wait time comments: mean 178, SD 124 minutes vs other comments: mean 143, SD 84 minutes, $\mathrm{p}=0.039$ ) total ED times. Reported total ED time was significantly longer 
Table I Press Ganey Survey Questions

\begin{tabular}{|c|c|}
\hline Section & Questions \\
\hline \multirow[t]{6}{*}{ Arrival } & Waiting time before noticed arrival \\
\hline & Helpfulness of first person \\
\hline & Comfort of waiting area \\
\hline & Waiting time to treatment area \\
\hline & Waiting time to see doctor \\
\hline & Comments \\
\hline \multirow[t]{6}{*}{ Nurses } & Nurses' courtesy \\
\hline & Nurse took time to listen \\
\hline & Nurses' attention to your needs \\
\hline & Nurses' informative re treatments \\
\hline & Nurses' concern for privacy \\
\hline & Comments \\
\hline \multirow[t]{5}{*}{ Doctors } & Doctors' courtesy \\
\hline & Doctor took time to listen \\
\hline & Doctor informative re treatment \\
\hline & Doctors' concern for comfort \\
\hline & Comments \\
\hline \multirow[t]{6}{*}{ Tests } & Courtesy of person who took blood \\
\hline & Concern blood draw comfort \\
\hline & Waiting time for radiology test \\
\hline & Courtesy of radiology staff \\
\hline & Concern for comfort radiology test \\
\hline & Comments \\
\hline \multirow{4}{*}{$\begin{array}{l}\text { Family or } \\
\text { Friends }\end{array}$} & Courtesy shown family/friends \\
\hline & Adequacy of info to family/friends \\
\hline & Let family/friend be with you \\
\hline & Comments \\
\hline \multirow{4}{*}{$\begin{array}{l}\text { Personal/ } \\
\text { Insurance Info }\end{array}$} & Courtesy during pers/insur info \\
\hline & Privacy during pers/insur info \\
\hline & Ease giving pers/insur info \\
\hline & Comments \\
\hline
\end{tabular}

(Continued) 
Table I (Continued).

\begin{tabular}{|l|l|}
\hline Section & Questions \\
\hline Personal Issues & Informed about delays \\
\cline { 2 - 2 } & Staff cared about you as a person \\
\cline { 2 - 2 } & How well pain was controlled \\
\cline { 2 - 2 } & Information about home care \\
\cline { 2 - 2 } & Comments \\
\hline \multirow{2}{*}{ Assersment } & Overall rating ER care \\
\cline { 2 - 2 } & Likelihood of recommending \\
\cline { 2 - 2 } & Comments \\
\hline
\end{tabular}

than actual total ED time for both patients who submitted wait time comments (reported: mean 269, SD 109 minutes, actual: mean 180, SD 125 minutes, $\mathrm{p}<0.001$ ) and other comments (reported: mean 192, SD 88 minutes, actual: mean 144, SD 84 minutes, $\mathrm{p}<0.001)$. Reported and actual wait times for patients based on gender, language, and shift seen are displayed in Table 2.

\section{Effect of Trainee Presence on Total ED Time}

Of the 156 negative comments, the most common complaint pertained to the wait time $(45,27.7 \%)$, followed by dissatisfaction with assessment and plan (24, 14.8\%), courtesy of doctors and staff (19, 11.7\%), and grievances about COVID-19 restrictions $(18,11.1 \%)$. Five $(3.1 \%)$ of the comments specifically mentioned inexperience of trainees as a reason for grievance. Information about management team was available for 38 patients who submitted negative comments. These patients were most often seen by a resident who was supervised by an attending (29, 76.3\%). Less often the patient was seen by an attending alone $(5,13.2 \%)$ or an optometrist $(2,5.3 \%)$. Patients seen by a management team including a resident had significantly longer total ED times than those seen by a management team without a resident (resident: 152.9 minutes, non-resident: 84.6 minutes, $\mathrm{p}=0.015$ ). There was no significant difference in reported total ED times for resident vs non-resident management teams (resident: 187.7 minutes, non-resident 220.0 minutes, $\mathrm{p}=0.467)$.

Table 2 Negative Comment Characteristics

\begin{tabular}{|c|c|c|c|c|c|c|c|c|c|c|c|}
\hline & & \multicolumn{2}{|c|}{$\begin{array}{l}\text { \# Negative } \\
\text { Comments }\end{array}$} & \multicolumn{3}{|c|}{$\begin{array}{c}\text { \# Negative Comments per } \\
\text { Survey }\end{array}$} & \multicolumn{2}{|c|}{$\begin{array}{l}\text { Reported Wait } \\
\text { Time (Min) }\end{array}$} & \multicolumn{2}{|c|}{$\begin{array}{c}\text { Actual Wait Time } \\
\text { (Min) }\end{array}$} & \multirow[b]{2}{*}{$\mathbf{p}^{\mathbf{b}}$} \\
\hline & & $\mathbf{n}$ & $\%$ & Mean & SD & $\mathbf{p}^{\mathbf{a}}$ & Mean & SD & Mean & SD & \\
\hline \multirow[t]{2}{*}{ Gender } & Male & 109 & 69.9 & 1.53 & 0.92 & 0.234 & 191 & 78 & 146 & 68 & $<0.001$ \\
\hline & Female & 47 & 30.1 & 1.81 & 1.39 & & 228 & 110 & 157 & 113 & $<0.001$ \\
\hline \multirow[t]{2}{*}{ Language } & English & 58 & 37.2 & 1.73 & 1.30 & 0.668 & 220 & 93 & 149 & 91 & $<0.001$ \\
\hline & Spanish & 98 & 62.8 & 1.62 & 1.05 & & 199 & 114 & 161 & 112 & 0.021 \\
\hline \multirow[t]{3}{*}{ Shift } & 7AM-3PM & 73 & 46.8 & 1.55 & 0.90 & 0.390 & 207 & 104 & 157 & 86 & $<0.001$ \\
\hline & 3PM-IIPM & 66 & 42.3 & 1.69 & 1.32 & & 220 & 105 & $|5|$ & 117 & $<0.001$ \\
\hline & IIPM-7AM & 17 & 10.9 & 2.83 & 2.14 & & 219 & 48 & 138 & 54 & $<0.001$ \\
\hline
\end{tabular}

Notes: ${ }^{a}$ Independent sample $t$-test (gender, language) or Kruskal-Wallis (shift) between groups. ${ }^{b}$ Paired sample $t$-test within groups.

Abbreviations: ED, emergency department; ESI, Emergency Severity Index; PG, Press Ganey. 


\section{Discussion}

Overall, analysis of PG reports submitted by patients seen in an ophthalmology ED at an academic institution demonstrated important distinctions in demographics and total ED time between patients. Of note, females submitted more negative comments than their male counterparts. This difference in response rates to patient satisfaction surveys by gender has been demonstrated in the literature, and it may be extrapolated that this variation applies to survey comments as well. ${ }^{2,4}$

The majority of patients who submitted negative comments were treated by a management team that included a resident. At the institution studied, ED patients are triaged by the charge nurse according to the Emergency Severity Index (ESI), with optometrists evaluating patients with ESI levels 3-5 during daytime working hours and ophthalmology residents and attendings evaluating patients with all ESI levels 24 hours a day. A prior study conducted at an academic ophthalmology department revealed decreased efficiency for outpatient appointments in the presence of trainees, with appointments with residents being $32 \%$ longer than those without residents. ${ }^{10}$ Based on our analysis, this finding also applies to the ophthalmologic ED setting. Inclusion of residents in management teams was associated with a longer time spent in the ED, which may be a result of the need for collaboration, multiple exams, and longer times taken to complete a history and exam at the trainee level. Interestingly, the patient self-reported total ED time was not significantly different based on inclusion of residents in the management team. A possible explanation may be that the presence of residents decreases the time to initial provider contact, creating the perception of decreased waiting time and thus decreased overall time spent in the ED. Nonetheless, these findings demonstrate the difficult balance between maintaining trainee education and providing efficient care for patients.

Analysis of total ED times of patients submitting negative comments demonstrated that patients were not accurate reporters and tended to overestimate the amount of time they spent in the ED, whether or not they submitted wait time complaints. However, patients complaining about wait time did spend significantly longer in the ED than those with other complaints. Prior literature has demonstrated that longer wait times correlate with patient complaints in EDs, although to our knowledge, this data does not exist for ophthalmic EDs. ${ }^{13}$

A limitation of this study was a low response rate. Only 92 of 9304 patients visiting the ED within the specified time range submitted negative comments. Patients were invited to complete PG surveys via an email following their visit, and while comments were invited, they were not required. Thus, the comments studied are likely unrepresentative of all patients visiting this institution's ophthalmic ED. Furthermore, management team information was only available for 38 of the 92 patients, and thus, conclusions about the effect of trainee presence may also not be entirely representative of the population. The short time span for which data was collected hinders the ability to generalize these findings. This is particularly true considering the impact COVID-19 may have had on the ED volume, patient demographics, and complaints for which patients presented to the ED. Also, this study incorporated data from only one institution, so findings may not accurately represent populations at other institutions and geographical regions with varying racial and ethnic compositions, medical literacy, and availability of ophthalmic EDs.

\section{Conclusion}

In conclusion, while PG survey results were found to be inaccurate representations of the overall ED population, analysis of data from negative comments offered insight into the validity of wait time complaints and effect of trainee presence on total ED time. The data indicate that while patients tended to overestimate time spent in the ED, patients complaining about wait time and seen by a management team that included a resident did have significantly longer total ED times. The implications of a prolonged waiting in the emergency room have been described, which highlight the need for efficiency and adequate staffing. ${ }^{6,7,14,15}$ While this task is complicated when institutional objectives include providing quality trainee education, efforts aimed at improving overall efficiency should focus on optimizing workflow and trainee efficiency.

\section{Funding}

There is no funding to report. 


\section{Disclosure}

Dr Jayanth Sridhar reports personal fees from Alcon, Dorc, Regeneron, and Genentech, outside the submitted work. The authors report no other conflicts of interest in this work.

\section{References}

1. History \& Mission. Press Ganey; 2020. Available from: https://www.pressganey.com/about/history-mission. Accessed January 7, 2020.

2. Compton J, Glass N, Fowler T. Evidence of selection bias and non-response bias in patient satisfaction surveys. Iowa Orthop J. 2019;39 (1):195-201.

3. Long C, Tsay EL, Jacobo SA, Popat R, Singh K, Chang RT. Factors associated with patient Press Ganey satisfaction scores for ophthalmology patients. Ophthalmology. 2016;123(2):242-247. doi:10.1016/j.ophtha.2015.09.044

4. Tyser AR, Abtahi AM, McFadden M, Presson AP. Evidence of non-response bias in the Press-Ganey patient satisfaction survey. BMC Health Serv Res. 2016;16(1):350. doi:10.1186/s12913-016-1595-z

5. Ngongo BT, Carlier A, Mols P. [Patient complaints in a hospital emergency department in Belgium]. Rev Med Liege. 2011;66(4):199-204. French.

6. Bernstein SL, Aronsky D, Duseja R, et al. The effect of emergency department crowding on clinically oriented outcomes. Acad Emerg Med. 2009;16(1):1-10. doi:10.1111/j.1553-2712.2008.00295.x

7. Hoot NR, Aronsky D. Systematic review of emergency department crowding: causes, effects, and solutions. Ann Emerg Med. 2008;52(2):126-136. doi:10.1016/j.annemergmed.2008.03.014

8. Shirodkar AL, Yeo DC, Shuttleworth MG. Trainee confidence managing ocular trauma. Eye (Lond). 2019;33(4):691-692. doi:10.1038/s41433-0180328-4

9. Swampillai AJ, Nowak VA, Maubon L, et al. Confidence of UK ophthalmology registrars in managing posterior capsular rupture: results from a national trainee survey. Ophthalmol Ther. 2022;11(1):225-237. doi:10.1007/s40123-021-00425-3

10. Goldstein IH, Hribar MR, Read-Brown S, Chiang MF. Association of the presence of trainees with outpatient appointment times in an ophthalmology clinic. JAMA Ophthalmol. 2018;136(1):20-26. doi:10.1001/jamaophthalmol.2017.4816

11. Goldstein IH, Hribar MR, Sarah RB, Chiang MF. Quantifying the impact of trainee providers on outpatient clinic workflow using secondary EHR data. AMIA Аnnu Symp Proc. 2017;2017:760-769.

12. Genuis ED, Doan Q. The effect of medical trainees on pediatric emergency department flow: a discrete event simulation modeling study. Acad Emerg Med. 2013;20(11):1112-1120. doi:10.1111/acem.12252

13. Spechbach H, Rochat J, Gaspoz J-M, Lovis C, Ehrler F. Patients' time perception in the waiting room of an ambulatory emergency unit: a crosssectional study. BMC Emerg Med. 2019;19(1):41. doi:10.1186/s12873-019-0254-1

14. Pines JM, Hollander JE. Emergency department crowding is associated with poor care for patients with severe pain. Ann Emerg Med. 2008;51 (1): $1-5$. doi:10.1016/j.annemergmed.2007.07.008

15. Vainieri M, Panero C, Coletta L. Waiting times in emergency departments: a resource allocation or an efficiency issue? BMC Health Serv Res. 2020;20(1):549. doi:10.1186/s12913-020-05417-w

Clinical Ophthalmology

\section{Dovepress}

\section{Publish your work in this journal}

Clinical Ophthalmology is an international, peer-reviewed journal covering all subspecialties within ophthalmology. Key topics include: Optometry; Visual science; Pharmacology and drug therapy in eye diseases; Basic Sciences; Primary and Secondary eye care; Patient Safety and Quality of Care Improvements. This journal is indexed on PubMed Central and CAS, and is the official journal of The Society of Clinical Ophthalmology (SCO). The manuscript management system is completely online and includes a very quick and fair peer-review system, which is all easy to use. Visit http://www. dovepress.com/testimonials.php to read real quotes from published authors.

Submit your manuscript here: https://www.dovepress.com/clinical-ophthalmology-journal 